\section{Avances en la lucha contra la hepatitis $\mathbf{B}^{1}$}

Se basa en: Organización Mundial de la Salud. Hepatitis B vaccine: making global progress. EPI Update 31.1996. Ginebra: OMS; 1996.
La infección por virus de hepatitis B (VHB) es un alarmante problema de salud pública en muchas partes del mundo. Aproximadamente 2000 millones de personas viven en zonas donde la prevalencia de hepatitis crónica es mayor de $2 \%$ y donde la enfermedad afecta a cerca de 350 millones de individuos. Estos son un reservorio de la infección y exponen a las personas susceptibles a un gran riesgo de enfermarse.

Se ha establecido que el VHB causa $80 \%$ de los casos de cáncer hepático primario y cirrosis en todo el mundo. Todos los años mueren por cirrosis o cáncer primario del hígado causado por VHB alrededor de un millón de personas. De ellas, 25\% son portadoras crónicas del virus.

En las zonas endémicas, la mayor parte de las infecciones se transmiten durante la infancia. La forma de contagio más frecuente es la perinatal o vertical (de la madre al niño). Otras formas importantes de transmisión, además del contagio horizontal de niño a niño, son el uso de agujas hipodérmicas contaminadas, la transfusión de productos derivados de la sangre no tamizados, el contacto sexual y la exposición ocupacional de los trabajadores de la salud.

Debido a la forma de contagio de la enfermedad, los niños pequeños corren el mayor riesgo de infección por VHB. Además, la probabilidad de convertirse en un portador crónico aumenta cuando la exposición al virus ocurre durante la infancia. Por esta razón, de 70 a $90 \%$ de los recién nacidos infectados se convierten en portadores, mientras que la infección crónica persiste en solo 5 a $10 \%$ de los adultos con infección aguda por VHB. El resto de individuos contagiados eliminan el virus de su organismo y no manifiestan efectos a largo plazo.

\section{VACUNA CONTRA LA HEPATITIS B}

La vacuna anti-VHB es el mejor medio de prevención contra la infección causada por el virus. Además, debido a las secuelas que produce la enfermedad en una alta proporción de pacientes crónicos, la vacuna también puede considerarse la primera forma de inmunización contra un tipo de cáncer.

Esta vacuna, que proviene del antígeno de superficie del virus de la hepatitis B (HBsAg), se 
fabrica a partir de derivados del plasma o de ADN recombinado. En el primer método, se obtiene el plasma de pacientes con la forma crónica de la enfermedad, el cual se procesa para destruir los virus. Se ha determinado que las vacunas producidas por cualquiera de los dos métodos confieren protección en $95 \%$ de los individuos inmunizados.

En un principio, se pensó que la elaboración de la vacuna a partir del antígeno de superficie incrementaría el riesgo de transmisión del virus de la inmunodeficiencia humana (VIH). Sin embargo, la forma de fabricación asegura que ningún agente infectante sobreviva. La administración de millones de dosis desde 1982 confirma que esa preocupación era infundada.

La vacuna contra la hepatitis B debe almacenarse a una temperatura de 2 a $8^{\circ} \mathrm{C}$. Es necesario evitar que se congele, lo que la desnaturaliza y destruye su potencia. La dosis, que varía según el fabricante, se debe administrar por vía intramuscular. Después de completar el esquema de tres dosis se producen excelentes tasas de seroconversión, usualmente mayores de $90 \%$. Se sugiere aplicarla junto con otras vacunas para evitar contactos adicionales con los servicios de vacunación. La vacuna se puede administrar en el momento de inmunizar contra el sarampión, la difteria, la tos ferina y el tétanos (DTP) o contra la poliomielitis, la tuberculosis o la fiebre amarilla. Se trata de una de las vacunas más seguras de las que se dispone en la actualidad. Las reacciones son poco frecuentes y suelen ser leves.

\section{ESTRATEGIA DE VACUNACIÓN}

En 1992, la Asamblea Mundial de la Salud propuso que la vacuna anti-VHB fuera introducida en 1995 en el esquema de inmunización de los países con prevalencias de portadores crónicos mayores de $8 \%$ y, para 1997, en todos los países. En el Noveno Programa General de Trabajo de la OMS se estableció la meta de reducir en $80 \%$ la tasa de portadores nuevos en niños mediante la introducción de esta vacuna en los programas nacionales de inmunización.

En los lugares donde el principal patrón epidemiológico de transmisión es vertical, la primera dosis debe administrarse lo antes posible después del nacimiento. Por otra parte, si el patrón de contagio es horizontal, la primera dosis puede aplicarse junto con la primera dosis de la DTP.

Se ha encontrado que la vacunación de adultos en grupos de alto riesgo en países con baja prevalencia no ha logrado controlar esa enfermedad en la población. No obstante, las personas en riesgo de contraer la infección se deben vacunar. Por tal motivo, muchos países industrializados han incor- porado esa vacuna en el esquema pediátrico de vacunación. Asimismo, en zonas donde predomina la transmisión por el uso común de agujas o por actividad sexual, como en el Canadá y los Estados Unidos de América, se vacuna a los adolescentes para lograr un mayor impacto en el control de la transmisión de la enfermedad.

El costo de una dosis pediátrica de la vacuna derivada de plasma varía de US\$ 0,50 a $\$ 1,00$, mientras que el costo de la vacuna por recombinación de ADN es más alto. Sin embargo, aun a $\$ 0,50$, cada una de las tres dosis de vacuna contra la hepatitis $B$ cuesta más que las seis vacunas restantes del Programa Ampliado de Inmunización. Por lo tanto, en muchos países en desarrollo con alta prevalencia de transmisión aún no se ha incorporado esa vacuna dentro del esquema nacional de inmunización. En la mayor parte de los países con alta prevalencia de VHB se está aplicando la vacuna, pero los países más pobres - generalmente con un producto interno bruto per cápita menor de $\$ 500$ - no la utilizan.

Recientemente se ha elaborado una vacuna cuadrivalente DTP-HB que dentro de poco estará disponible en el mercado. Esta combinación dará como resultado muchos beneficios y menos gastos. Sin embargo, los países no deben esperar hasta que aparezcan las vacunas combinadas para iniciar la vacunación contra la hepatitis $B$.

\section{SYNOPSIS}

\section{Advances in the fight against hepatitis}

Infection with hepatitis B virus ( $H B V)$ is responsible for $80 \%$ of the cases of primary liver cancer and cirrhosis worldwide. Every year almost a million people, of whom $25 \%$ are chronic carriers of the virus, die from these diseases. Anti$H B V$ vaccine is the best means of prevention and can be considered the first immunization against a type of cancer, owing to the sequelae that hepatitis produces in many chronically infected patients. This vaccine is made from the surface antigen of hepatitis B virus (HBsAg); it is manufactured from plasma derivatives or through recombinant DNA and confers up to $95 \%$ protection. It is suggested that this vaccine be given at the same time as other vaccines to avoid the need for additional contacts with the immunization services.

In 1992 the World Health Assembly proposed that the vaccine should be available in all countries by 1997. In its Ninth General Program of Work, WHO established the goal of reducing the number of new carriers by $80 \%$ through the introduction of this vaccine into national child immunization programs. Recently, a quadrivalent DTP-HB vaccine has been produced, resulting in increased benefits and lower cost. However, countries should not wait until the combined vaccines are marketed to begin vaccination against hepatitis $B$. 